\title{
PRAGMATIC DEFICITS OF ASPERGER SYNDROME
}

\author{
Silmy Arizatul Humaira'
}

Email: humairasilmy@gmail.com

Jurusan Bahasa dan Sastra Inggris Fakultas Humaniora UIN Malang

Alamat Korespondensi: Jalan Gajayana 50 Malang 65144

\begin{abstract}
Human being is social creature who needs other people to interact with. One of the ways to interact with others is communication with language. However, communication could be a complicated problem for those who were born with developmental disorder called Asperger Syndrome (AS). The communication challenge of Asperger's is the difficulty using language appropriately for social purposes or known as pragmatic deficits. Many excellent books about autism are published whereas knowledge on pragmatic deficits are still very limited. Thus, it is expected to be a beneficial reference to understand the pragmatic deficits and to create strategies for them to communicate effectively. Therefore, this study aimed at exploring the kinds of pragmatic deficits of an individual with AS. The verbal language profiles of autism purposed by MacDonald (2004) is used to analyzed the data in depth. The descriptive qualitative method is applied to develop a comprehensive understanding about the AS case in Temple Grandin movie.The finding shows that all of the five types of communication deficits are appearing and the dominant of which is unresponsive..
\end{abstract}

Keywords: Asperger Syndrome (AS), Pragmatic Deficits.

\section{INTRODUCTION}

Pragmatic deficits noticed in all of people with autism. It means that individuals with autism struggle with the social use of language. When the language use is disrupted, people have problem with using the language for communication purpose. Despites of many excellent books about autism are published, knowledge on pragmatic deficits are still very limited. Therefore, this study is conducted to provide empirical explanations about pragmatic deficits in social communication.

The movie entitled Temple Grandin released in 2010 is the representative of pragmatic deficits phenomenon. It is shown in the movie that a person named Temple Grandin has extreme social problems dealing with the difficulties to communicate or interact with people surround her. This movie becomes a valuable source to observe deeply because it exposes the real story taken from the life experince of Temple Grandin, an expert on animal handling who has been diagnosed as having Asperger Syndrome (AS), one of the kinds of Autism Spectrum Disorder (ASD), (Lerner \& Johns, 2015, p. 193).

This study aimed at investigating the kinds of pragmatic deficits occur in AS character. It focuses on psycholingistics field especially on communication disorder and pragmatics deficits experienced by the AS character in the movie. However, it concerns on verbal or oral language and it does not deal with non-verbal pragmatic deficits such as facial expression difficulties, speech intonation, gestures and other similar traits.

Theoretically, this paper applies psycholinguistics theories concerning on communication disorder integrated with pragmatics to provide a valuable insight on how an individual with AS communicates with other people. Meanwhile, practically this study attempts to be beneficial and comprehensive reference for professionals, lecturers, students, clinician, language pathologists, therapyst, and for those who are interested in 
enhancing their knowledge about AS and to deepen the understanding about thepragmatic deficits experienced by them.

So far, there are few prior studies which concern on pragmatic deficits of those with AS. The reason is because many reserachers focus on analyzing the differences and similarities among developmental disorders such as autism, Autistic Disorder (AD), Asperger Syndrome (AS), High Functioning Autism (HFA), Attention Deficit Hyperactivity Disorder (AD/HD) and many more (Sanders, 2009; Helland, Biringer, Helland, \& Heimann, 2012; Todorov \& Arnaoudova, 2012). They attempt to explore the language profiles to be taken into account for standardizing the diagnosis or the assessment of the disorders. For example, Helland, Biringer, Helland, \& Heimann (2012, p. 34) conducts a study aims to investigate the communication impairment of children with ADHD and AS. Their laguage profiles based on the Norwegian adaptation of Children's Communication Checklist Second Editin (CCC-2) are explored to differentiate their language abilities. The results are reported that language skills is important to be used to perform the standard assessments of $\mathrm{AD} / \mathrm{HD}$ and $\mathrm{AS}$ and to initiate therapies. From this previous study, it can be concluded that language skills including pragmatics skills is highly recommended to be observed further.

\section{REVIEW OF RELATED LITERATURE History And Diagnosis of Asperger Syndrome}

Historically, AS is first time identified by Kanner and Asperger in 1943 and 1944 (Mesibov, Shea \& Adams, 2002, p. 5) but, it became popular after Wing (1981) introduced the term "Asperger Syndrome" in English (as cited in Bowler, 2007, p. 5). Mesibov,Shea \& Adams (2002, p. 9) explained that both Kanner and Asperger noted symptoms of AS is in three areas called Triad of Impairment, including social difficulties, communication problems for both verbal and non-verbal, and repetitive and restricted activities.

According to APA (2013, p. 32), AS falls under the umbrella of ASD without language or intelectual impairment which is characterized by first, deficits in social communication and interaction and second, restricted repetitive behavior, interests and activities. Cotugno (2009, p. 24) noted that AS is considered as milder form of Autistic disorder (AuD). Besides, the caused of AS is not known yet, but Gillberg (2002, p. 78) states that genetic factors and brains injury/ brains damaging are believed to be the induced of the disorder.

To identify individual with AS, Mesibov, Shea \& Adams (2002, p. 35) points out that some professionals used two considerations, people with AS have some social interests and have better verbal skill although sounds unusual. As Hagland (2010, p. 112) states that the language of people with AS can be unusual for both content and expression. Moreover, it is emphasized by Kowalski (2005, p. 29) that pragmatic language is the core deficit in language communication of people with AS.

\section{Pragmatic Deficits}

Pragmatic skills defined by Sperber \&Wilson (2005) as cited in Perkins (2007, p. 9) as 'the study of the use of language' and more specifically as 'the study of how contextual factors interact with linguistic meaning in the interpretation of utterances. In other words, pragmatics deals with the individual choice and use of language that enable the person to use language appropriately in social context whereas pragmatic deficits deals with the deficits on the social use of language in appropriate context.

Eysenck \& Keane (2015, p. 412) explaines that individuals with AS experience social communication difficulties although they acquire a normal language development which means that they have impaired pragmatic language comprehension in social context. For example, Paul et al. (2009) explain that people with HFA (High Functioning Autism) and AS experience great problems in pragmatics such as topic management, information management and reciprocity (Ghaziuddin \&Gerstein, 1996) as cited by Paul, Landa \& Simmons (n.d.) in McPartland (2014, p. 116). Topic management related to giving comment related to the topic introduced by the partner, and introducing the topic relevance to the shared interest. Next, information management related to the information amount and type that should be provided as needed. Then, reciprocity related to the ability to produce and respond to 
conversational exchanges fot both verbal and non verbal.

As Gillberg (2002, p. 14) states that pragmatics is the great problem experienced by children and adults with AS eventhough they have excellent expressive language skills. They may know the meaning of each words and even have a good grammar skill but they often do not use the words appropriately in the certain contexts. Therefore, this problem often leads them to face difficulties in communicate interactively with other people. Furthermore, MacDonald (2004) proposed the five profiles of the verbal autistic children consisting of unbalanced, mismatched, unresponsive, lack of sharing control and lack of playfulness. Those profiles show that the child with autism or language disorder like those who have AS have communication challenges which make them look and sound different with their peers. These are the following profiles describes many verbal autistic spectrum children:

\section{Unbalanced.}

There is little give and take and neither person waits for the other to talk. One partner is often doing most of the talking with little change for the other to talk

2. Mismatched.

Often the two persons are not really talking about the same thing, or one person is doing much more of the talking than the other.

3. Unresponsive.

One person often feels that the other is not responding genuinely to them but is just talking at them. The person may be ignoring the other or just talking at them. The person may be ignoring the other or just not responding to what the other is saying or meaning.

4. Lack of sharing control.

One partner makes most of the decisions and directions as the other plays a passive or resistant role. The conversation often seems stuck and there is no apparent development of a topic.

5. Lack of playfulness.

The conversation is usually more tense and task-oriented than relaxed and seldom reflects much humor. (2004, p. 208-209).

\section{METHOD}

This study applies descriptive qualitative method since it generates the data in words about the specific individual in specific context. It aims at developing a detailed understanding about a case on how an individual with AS experienced pragmaticdeficits. Besides, the data collected in this study is descriptive so that the reader can understand what happened to Temple Grandin as individual with AS and how she experienced pragmatic deficits. In this case, the social communication difficulties which occur in the movie become the main source to be observed.

After observing the whole movie, the subtitles are transcribed. Then, the data are documented by collecting the conversations between AS character with others which represent the communication difficulties. Mainly, concerned on noting Temple's expressions to other characters and responses toward what has been said. Next, each datum is classified based on MacDonald's theory (2004). It is also urgent to note that the data are minimized by selecting them regarding to the research problems.

Then, each datum is analyzed in depth and is interpreted logically. The relevant theories are considered to support the process of analysis. Furthermore, the results of the study are reported. The data source triangulation is used to establish the credibility of the findings in which the movie's transcript taken from movie's subtitle downloaded is compared to the script written manually.

\section{FINDINGS AND DISCUSSION}

The results of analysis decipher the five profiles of the verbal autistic children are not only suitable for children with autism disorder but also match for adults with AS. Therefore, it means that the pragmatic deficits could still remain occuring until the people with AS grown up as adult. Moreover, all of kinds of pragmatic deficits proposed by MacDonald (2004) such as unbalanced, mismatched, unresponsive, lack of sharing control and lack of playfulness occured in the conversations between Temple and her partners of talk, but the most frequent type appearing in the conversation is unresponsive. However, the occurence of the unappropriate expressions or 
responses are not always presenting in all entire contexts of conversation because there is some expressions and responses which utter well and can be accepted by the partner of talk.

Unresponsive is the situation when a speaker in the conversation is ignored by the partner and the partner does not give respond to what speaker said. Gillberg (2002, p. 96) explaines that people with AS appear to live in their own world and does not appear to listen what people speak to them. In accordance with Gillberg's explanation, the example of unresponsive conversation can be seen in the conversation below:

Ann : You're right. How'd you figure that out?

Billy : There you go!

Temple: What are they doing?

Temple's aunt named Ann ask Temple about a horse but Temple does not answer that and she ignores her aunt because she wonders what Billy is doing. Another example is,

Ann : You don't have to decide just yet, do you? It's better than boarding school.

That's great. Lots of choices...

Temple: Danny's looking at you. See? He can see all around without moving his head.

Thus, those examples show that Temple appears unressponsive because she does not give any response to the partner of talk. Despites of giving an appropriate answer to the given question, she shifts the topic into another topic. Importantly, this unresponsiveness occurs frequently in the conversations for many times.

Besides, there is also some unbalanced conversations occur when Temple talks non stop about a certain topic. She wants to tell others about a certain topic and she wants them to pay attention and listen to her, without any regard to the listener's feelings on whether they are interested or not with the topic. So, it seems that she does not understand the appropriate topic and situation to talk with others. According to this context, Gillberg (2002, p. 27) states that people with AS may speak at length about their favorite interest and not noticing other people reactions toward what they say. Therefore, it is common for them to talk much about a special topic which is related to their interest and even neglecting the listener.
In this case, mismatched, refers to the situation when two people seem do not talk the same thing, is sometimes also occurs in the conversations. Futhermore, Hagland (2010, p. 115) explaines that people with AS are having difficulty in understanding other people point of view, social rules, non-verbal cues, and emotional signals which happens because they lack of "theory of minds" that makes them difficult to understand or guess what people around them likely think or feel. In accordance with that condition, people with AS just think from their own perspectives, fail to understand another person's point of view and tend to say whatever comes to their mind.

As it has been explained previously that those with AS have theory of mind deficits, consequently, lack of playfullness are sometimes occurs in certain and contexts but not frequently. Hagland (2010, p. 22) states that those with AS often take everything literally because of poor comprehension. Meanwhile, lack of playfulness refers to the situation when the conversation tends to be very serious, because it seldom refrects humor. Moreover, Lindblad (n.d., p. 127) explains that the people with AS also has a problem with receptive language skills, for instance, in understanding deeper meaning in words, phrases, and social situation. So, it is common for them to be too serious because they just understand the real or explicit meaning whereas does not understand the figurative or implicit meaning. Therefore, because people with AS often take everything seriously, they might easily misunderstand what other people said in certain condition.

Hagland (2010, p. 99) has mentioned that people with AS sometimes seems to not listen what is being said and even interupt other with something irrelevant to the topic of conversation. It is relevance to the lack of sharing control concept. It happens in a certain situation when a person makes all the desicion and direction while the others are playing a passive role. In other words, one of the speaker has more power to settle the topic of the conversation under his or her willing while the other one passively follow the direction of the partner of talk. The movie shows that sometimes but not veryoften, the conversations indicate that Temple lacks of sharing control. She dominates the 
conversation and maintains the topic based on her own willingness.

\section{CONCLUSIONS}

In conclusion, all of the kinds of pragmatic deficits such as unbalanced, mismatched, unresponsive, lack of sharing control, and lack of playfulness occur in the conversations in Temple Grandin movie, despites of some expressions and responses which are uttered well by Temple Grandin and that can be accepted by the partner of talk. Furthermore, the results of this study indicate the most frequent type of language deficits occurs in the conversation is unresponsive. So, the listener should understand this situation and does not misunderstand with their ignorance.

\section{REFERENCE}

APA (American Psychiatric Association). (2013). Diagnostic and statistical manual of mental disorder ( $5^{\text {th }}$ ed.). Arlington: American Psychiatric Publishing.

Bowler, D. M. (2007). Autism spectrum disorder: psychological theory and research. London: John Wiley \& Sons, Ltd.

Cotugno, A. J. (2009). Group intervention for children with autism spectrum disorders: a focus on social competency and social skills. London: Jessica Kingsley Publishers.

Eysenck M. W., \& Keane M. T. (2015). Cognitive psychology: a student handbook (7th ed.). New York: Psychology Press.

Gillberg, C. (2002). A guide to asperger syndrome. Cambridge: Cambridge University Press.

Hagland, C. (2010). Getting to grips with asperger syndrome: understanding adults on the autism spectrum. London: Jessica Kingsley Publishers.

Helland, W. A., Biringer, E., Helland, T., \& Heimann, M. (2012). Exploring language profiles for children with AD/HD with AS. Journal of Attention Disorders, 16(1) (pp. 34-43). UK: Sage Publication.

Kowalski, T. P. (2005). Assessing communication skills in asperger's syndrome: an introduction to the conversational effectiveness profile. Florida Journal of Communication Disorders, 22, 2934.

Lerner, J. W., \& Johns, B. (2015). Learning Disabilities and Related Disabilities: Strategies for Success (13 $3^{\text {th }}$ ed). Stamford: Cengange Learning.

Lindblad, T. (n.d.). Communication and Asperger Syndrome:The speech-language pathologist's role. In Stoddard , K. P. (Ed.). Children, youth and adults with asperger syndrome integrating multiple perspectives (pp. 125-139). London: Jessica Kingsley Publishers.

MacDonald, J. D. (2004). Communicating partners : 30 years of building responsive relationships with late-talking children including autism, Asperger's syndrome (ASD), Down syndrome, and typical development developmental guides for professionals and parents. Philadelphia: Jessica Kingsley Publishers.

Mesibov, G. B., Shea, V., \& Adams, L. W. (2002). Understanding asperger syndrome and high functioning autism. New York: Kluwer Academic Publishers. 
Paul, Landa \& Simmons (n.d). Communication in asperger syndrome. In McPartland, J.C., Klin, A., \& Volkmar F. R. (Eds.). Asperger syndrome assessing and threating high-functioning autism spectrum disorders (2nd, pp.103-139). New York: The Guilford Press.

Perkins, M. (2007). Pragmatic impairment. New York. Cambridge University Press.

Sanders, J. L. (2009). Qualitative or quantitative differences between asperger's disorder and autism? historical consideration. J Autism Dev Disord, 39, 1560-1567.

Todorov, S., \& Arnaoudova, M. (2012). On diferential diagnosis between autistic disorder and asperger's syndrome. Journal of IMAB, 18, 334-336. 